\title{
Relevance of coral geometry in the outcomes of the coral-algal benthic war
}

2

Emma E. George ${ }^{1,2}$, James Mullinix ${ }^{3,4,5}$, Fanwei Meng ${ }^{3}$, Barbara Bailey ${ }^{3,5}$, Clinton Edwards ${ }^{6}$, Ben Felts ${ }^{3,5}$, Andreas Haas ${ }^{7}$, Aaron C. Hartmann ${ }^{1,8}$, Benjamin Mueller ${ }^{9,10}$, Jim Nulton ${ }^{3,5}$, Ty N.F. Roach $^{1,5}$, Peter Salamon ${ }^{3,5}$, Cynthia B. Silveira ${ }^{1,5}$, Mark J.A. Vermeij ${ }^{9}{ }^{10}$, Forest L. Rohwer ${ }^{1,5}$, Antoni Luque*3,4,5

${ }^{1}$ Department of Biology, San Diego State University, San Diego, CA, USA

${ }^{2}$ Department of Botany, University of British Columbia, Vancouver, BC, Canada

${ }^{3}$ Department of Mathematics and Statistics, San Diego State University, San Diego, CA, USA

${ }^{4}$ Computational Science Research Center, San Diego State University, San Diego, CA, USA

${ }^{5}$ Viral Information Institute, San Diego State University, San Diego, CA, USA

${ }^{6}$ Scripps Institution of Oceanography, University of California San Diego, San Diego, CA, USA

${ }^{7}$ NIOZ Royal Netherlands Institute for Sea Research and Utrecht University, Texel, Netherlands

${ }^{8}$ Smithsonian National Museum of Natural History, Washington, DC, USA

${ }^{9}$ CARMABI Foundation, Willemstad, Curaçao

${ }^{10}$ Department of Freshwater and Marine Ecology/Institute for Biodiversity and Ecosystem Dynamics, University of Amsterdam, Amsterdam, The Netherlands

*Corresponding author: Antoni Luque

Department of Mathematics and Statistics, GMCS 512

San Diego State University

5500 Campanile Dr.

San Diego, CA 92182-4614

Phone: 619-594-1336

Fax: 619-594-5676

Email: aluque@mail.sdsu.edu 
40 Abstract: Corals have built reefs on the benthos for millennia, becoming an essential element in

41 marine ecosystems. Climate change and human impact, however, are favoring the invasion of

42 non-calcifying benthic algae and reducing coral coverage. Corals rely on energy derived from

43 photosynthesis and heterotrophic feeding, which depends on their surface area, to defend their

44 outer perimeter. But the relation between geometric properties of corals and the outcome of

45 competitive coral-algal interactions is not well known. To address this, 50 coral colonies

46 interacting with algae were sampled in the Caribbean island of Curaçao. 3D and 2D digital

47 models of corals were reconstructed to measure their surface area, perimeter, and polyp sizes. A

48 box counting algorithm was applied to calculate their fractal dimension. The perimeter and

49 surface dimensions were statistically non-fractal, but differences in the mean surface fractal

50 dimension captured relevant features in the structure of corals. The mean fractal dimension and

51 surface area were negatively correlated with the percentage of losing perimeter and positively

52 correlated with the percentage of winning perimeter. The combination of coral perimeter, mean

53 surface fractal dimension, and coral species explained 19\% of the variability of losing regions,

54 while the surface area, perimeter, and perimeter-to-surface area ratio explained $27 \%$ of the

55 variability of winning regions. Corals with surface fractal dimensions smaller than two and small

56 perimeters displayed the highest percentage of losing perimeter, while corals with large surface

57 areas and low perimeter-to-surface ratios displayed the largest percentage of winning perimeter.

58 This study confirms the importance of fractal surface dimension, surface area, and perimeter of

59 corals in coral-algal interactions. In combination with non-geometrical measurements such as

60 microbial composition, this approach could facilitate environmental conservation and restoration

61 efforts on coral reefs. 


\section{INTRODUCTION}

65 Corals use energy derived from photosynthesis and heterotrophic feeding to build reefs. This has enabled corals to dominate the battle for light and space on the reef benthos for millennia

67 (Kaandorp \& Kubler, 2001). However, the combination of overharvesting of herbivorous fish, increased nutrient runoff from land (eutrophication), and ocean warming is stimulating the growth of non-calcifying algae at the expense of corals world-wide (Alevizon \& Porter, 2015). The increase in algal coverage is re-routing the energy to alternative trophic pathways that are

71 enhancing the dominance of algae through positive feedback loops, for example, invigorating the

72 growth of opportunistic and virulent microbes at the coral-algal interface (Kline et al., 2006;

73 Smith et al., 2006; Dinsdale \& Rohwer, 2011, Silveira et al. 2015). As algal density increases on

74 reefs, competitive coral-algal interactions are becoming more frequent (Barott et al., 2012a,b;

75 Dinsdale \& Rohwer, 2011; Haas et al., 2011), and, in order to preserve and restore coral reefs, it

76 is crucial to understand the key factors that determine the outcomes of these interactions. herbivore biomass on coral-algal interactions, results have been somewhat equivocal (Smith et carbon (DOC) released by fleshy algae stimulates the growth of opportunistic microbes at the coral-algal interface (Dinsdale \& Rohwer, 2011). In combination with a shift to inefficient 
85 interface, weakening and killing coral tissues (Haas et al., 2013; Roach et al., 2017).

86 Simultaneously, the outcome of a competitive interaction with benthic algae depends on the

87 relative algae overgrowth rate as well as the percentage of the coral perimeter in contact with

88 macroalgae (Lirman, 2001). Thus, the coral perimeter and the ability to defend it must be a key

89 factor in determining the coral-algal interaction outcome.

90 A coral colony consists of multiple clonal polyps that are connected by the coenosarc

91 tissue. Polyps along the perimeter of the colony interact with invading non-calcifying algae as

92 well as other benthic organisms (Jackson, 1977 \& 1979; Buss \& Jackson, 1979; Meesters,

93 Wesseling \& Bak, 1996). At any competitive interaction zone a coral can either overgrow (win),

94 be overgrown (lose), or neither overgrow nor be overgrown (neutral) by the interacting species

95 (Figure S1A) (Jackson \& Winston, 1982; Barott et al., 2012b; Swierts \& Vermeij, 2016).

96 Defending the perimeter requires the allocation of resources. The energy obtained from

97 photosynthesis — carried out by endosymbiotic algae — and heterotrophic feeding (Porter, 1976)

98 is then distributed throughout the colony using the coenosarc tissue (Rinkevich \& Loya, 1989;

99 Oren et al., 1997; Henry \& Hart, 2005; Schweinsberg et al., 2015). As the colony’s surface area

100 increases so does its potential for nutrient acquisition and distribution (Oren et al., 2001). Thus,

101 coral surface area should be another key factor in determining the coral-algal interaction

102 outcome.

The resource availability hypothesis (RAH) (Endara \& Coley, 2011) predicts that fast

104 growing corals will rely on clonal growth strategies to indirectly outcompete the invading algae.

105 This explains the resilience observed among branching corals, which invest the resources 
acquired from their large surface areas to grow new polyps rather than to protect their small perimeters (Swierts \& Vermeij, 2016). In contrast, RAH predicts that slow growing species tend to face more encounters with competitors and will invest more resources in protecting their perimeters. This has been confirmed for slow growing corals like encrusting and massive corals (Swierts \& Vermeij, 2016).

The morphology and size of these slow growing corals have been linked to corals' natural competitive edge against most algal groups (Porter, 1976; Tanner, 1995). Massive corals have relatively lower perimeter-to-surface area ratios and demonstrate greater resilience to algal overgrowth compared to encrusting corals with large perimeter-to-surface area ratios (Hughes 1989; Tanner 1995; Lirman 2001). A coral-algal survey in the Line Islands observed that small and large corals were more effective winning against algae than medium sized corals $(40-80 \mathrm{~cm})$ (Barott et al. 2012b). In contrast, in the South China Sea it was observed that medium size corals won more often than small and large corals (Swierts \& Vermeij, 2016). Thus, the influence of the geometrical properties in the outcome of the coral-algal interaction remains unclear.

The accurate measurement of the perimeter and surface area in natural objects, however, is usually challenged by the presence of fractality (Mandelbrot, 1967, 1977, 1983). Fractals are non-smooth objects that display similar patterns across multiple scales. This makes the perimeter length and surface area to depend on the resolution of the measurement. In particular, the values follow a power law of the scale with an exponent related to the perimeter and surface's fractal dimensions, respectively, (Falconer 2003, Okie, 2013) (see Eq. (S1) in Methods). Higher fractal dimensions lead to more convoluted surfaces or perimeters with a larger number of wrinkles and 
127 textures that increase the effective surface and perimeter of corals (Falconer, 2003; Okie, 2013).

128 Previous studies found fractality among corals at different scales (Basillais, 1997; Bradbury \&

129 Reichelt, 1983; Knudby \& LeDrew, 2007; Martin-Garin et al., 2007; Mark, 1984; Purkis et al.,

130 2006; Reichert et al., 2017; Zawada \& Brock, 2009), but the measurements at the coral colony

131 scale of interest in the present study were inconclusive (Mark 1984).

$132 \quad$ Here we hypothesize that larger fractal dimensions and smaller perimeter-to-surface area

133 ratios would favor corals when facing competitive interactions with algae. To characterize the

134 fractal dimension accurately, high-resolution images of corals were necessary (Young et al.,

135 2017), so we applied new imaging and computer rendering technologies to obtain a systematic

136 and accurate analysis of coral geometry in the $1 \mathrm{~mm}$ to $1 \mathrm{~m}$ range.

\section{METHODS}

\section{$139 \quad$ Field sampling}

Photographs of 50 coral colonies in the Caribbean island of Curaçao were taken by

141 SCUBA diving using a Canon Rebel T4i with a 35-mm lens and two Keldan 800 lumen video

142 lights to illuminate the corals uniformly. An in-reef ruler was photographed to set the scale for

143 the digital models; the ruler was placed along the interface of the coral colonies. Additionally,

144 the perimeters of five coral colonies were measured in the field using a chain-link method, using

145 links of sizes $1.5 \mathrm{~cm}, 5.5 \mathrm{~cm}$, and $10.5 \mathrm{~cm}$. See Supplementary Material for additional details. 
High-resolution, overlapping images of coral perimeters were stitched together to build a

$1492 \mathrm{D}$ perimeter model (see Figures 1 and 2) using Globalmatch and Guimosrenderer software

150 (Gracias \& Santos-Victor, 2000, 2001; Lirman et al., 2007, 2010). The minimum threshold

151 resolution was $\sim 0.5 \mathrm{~mm}$. The interaction zones were outlined in separate RGB channels using

152 Adobe ${ }^{\circledR}$ Photoshop ${ }^{\circledR}$ CC 2014 (Figures 1 and 2): red (coral losing), green (coral winning), and

153 blue (neutral). The fraction of red, green, and blue pixels was used, respectively, to obtain the

154 percentage of losing $(\% \mathrm{~L})$, winning $(\% \mathrm{~W})$, and neutral $(\% \mathrm{~N})$ interactions around a coral

155 perimeter. See Supplementary Material for additional details.

156

157

$3 D$ coral models

158

Autodesk ${ }^{\circledR}$ ReMake ${ }^{\circledR}, 2016$ was used to create 3D coral models (Burns et al., 2015;

159 Leon et al., 2015) (Figures 1 and 2) to facilitated the accurate measurement of geometric

160 properties of corals, e.g., perimeter, surface area, and volume at multiple scales (Naumann et al., 1612009 \& Lavy et al., 2015). The resolution of the models ranged from $1.6 \mathrm{~mm}$ to $49 \mathrm{~mm}$ with an 162 average of $11 \mathrm{~mm}$. See Supplementary Material for additional details.

165 The fractal dimension was calculated using a box counting method (Falconer 2003). The

166 logarithm of the number of boxes was plotted against the logarithm of the box size, and the

167 fractal dimension $D$ was extracted from the slope of the linear regression using Eq. (S1) (Figure

168 S2). The $95 \%$ confidence intervals for the fractal dimension was calculated using a Monte-Carlo 
non-parametric bootstrap resampling method. The method was tested for the following fractal objects: the Koch curve, Sierpinski triangle, Menger sponge, and kidney vasculature. This lead to an error on the $1-3 \%$ range using five bisections (Table S1). The upper value of this range was used as the theoretical error for the fractal dimension. The perimeter fractal dimension $\left(\mathrm{D}_{\mathrm{P}}\right)$ was calculated from the 2D high-resolution models, which allowed a minimum of ten bisections in the algorithm. The surface fractal dimension ( $\left.\mathrm{D}_{\mathrm{S}}\right)$ was calculated from the 3D high-resolution models, which allowed a minimum of five bisections in the algorithm. The null hypotheses $\mathrm{D}_{\mathrm{P}} \neq$ 1 and $D_{S} \neq 2$ were evaluated using the nonparametric sign test. See Supplementary Material for additional details.

\section{Coral geometric properties: perimeter, surface area, volume, and polyp size}

The perimeter, surface area, and volume of the 3D models were calculated with the mesh report tool in Autodesk ${ }^{\circledR}$ Remake ${ }^{\circledR}, 2016$. This approach was previously tested in Naumann et al., 2009 and Lavy et al., 2015. The perimeter of the high-resolution 2D models was obtained using a Richardson algorithm. The values were compared with field values using three physical chain-links $(1.5 \mathrm{~cm}, 5.5 \mathrm{~cm}$, and $10.5 \mathrm{~cm})$ with an errors of $14.5 \%, 17.5 \%$, and $19.7 \%$, respectively (Table S2). This discrepancy was reasonable taking into the account the projection on the model and the measurement field error. The 2D perimeter used in the analysis was obtained using a $1 \mathrm{~mm}$ ruler in the Richardson algorithm. Polyp diameters were also measured from the $2 \mathrm{D}$ models using Image J $1.47 \mathrm{v}$ and averaging 10 polyp diameters per colony. See Supplementary Material for additional details. 


\section{Correlation with single variables}

A linear regression (least squares method) was used to compare the percentages of losing

$194(\% \mathrm{~L})$ and winning $(\% \mathrm{~W})$ perimeter with respect depth $(\mathrm{d})$, polyp diameter $\left(\mathrm{P}_{\mathrm{d}}\right)$, volume $(\mathrm{V})$,

195 surface area (SA), surface area-to-polyp area ratio $\left(\mathrm{SA}_{\text {polyp}}\right)$, perimeter fractal dimension $\left(\mathrm{D}_{\mathrm{P}}\right)$,

196 surface fractal dimension $\left(\mathrm{D}_{\mathrm{S}}\right), 2 \mathrm{D}$ perimeter obtained from Richardson's algorithm $\left(\mathrm{P}_{\mathrm{R}}\right), 3 \mathrm{D}$

197 perimeter length $\left(\mathrm{P}_{3 \mathrm{D}}\right), 3 \mathrm{D}$ perimeter-to-polyp size ratio $\left(\mathrm{P}_{\text {polyp }}\right), 2 \mathrm{D}$ perimeter-to-surface area

ratio $\left(\mathrm{P}_{\mathrm{R}} / \mathrm{SA}\right)$, and $3 \mathrm{D}$ perimeter-to-surface area ratio $\left(\mathrm{P}_{3 \mathrm{D}} / \mathrm{SA}\right)($ Table $\mathrm{S} 6)$. The neutral

interactions were a small fraction and were not studied in detail.

\section{Statistical learning: Random forest}

The package randomForest (Liaw \& Wiener, 2002) was used to analyze the response of

205 importance and p-value. metrics by permuting the dependent variable, producing a null

206 distribution of importance metrics, and calculating the p-value for each predictor variable. The

207 initial global analysis included 13 input variables: Species, depth, polyp diameter, volume,

208 surface area, volume to surface area ratio, surface to polyp diameter square ratio, projected

209 perimeter length, 3D perimeter length, 3D perimeter length to polyp diameter ratio, projected 
211 and surface fractal dimension. Both rfPermute and randomForest were run five times and

212 averaged separately to rank the variables independently based on the mean increase accuracy

213 error \%IncMSE values. The analysis combining the top ranked variables in groups of three, and

214 the combination leading to the largest variance explained was selected for further analysis. The

215 hierarchical visualization of these variables was obtained using the rpart package in R (Terry

216 2017) for $\% \mathrm{~L}$ and $\% \mathrm{~W}$. See Supplementary Material for additional details.

217

Coral geometric properties across Curaçao regions.

The corals sampled (n) were grouped in three geographical regions in the island of

221 indicators for the percentage of losing and winning interactions (fractal surface dimension,

222 surface area, perimeter length, and perimeter-to-surface area ratio) were compared using

223 boxplots.

\section{RESULTS}

\section{Coral-algal competition outcomes}

On average, coral displayed 60\% losing, 29\% winning, and 11\% neutral interactions

228 along the perimeter with algae (Figures 2a and 2b, and Table S5). Among species that were

229 sampled in five or more colonies, S. siderea displayed the largest percentage of losing perimeter

230 (81\%), followed by P. strigosa (69\%), M. cavernosa (58\%), and O. faveolata (56\%) (Figure 2c).

231 The species followed the inverse trend regarding the percentage of winning perimeter: $O$. 
232 faveolata (33\%), M. cavernosa (23\%), P. strigosa (19\%), S. siderea (12\%). The percentage of

233 neutral perimeter was smaller and followed a different trend: M. cavernosa (19\%), P. strigosa

$234(12 \%)$, O. faveolata $(11 \%)$, S. siderea $(8 \%)$. Thus, corals were generally losing, and the neutral

235 regions represented the smallest fraction of the competitive outcomes. On average, S. siderea

236 was the most vulnerable species, while $O$. faveolata was the most resilient.

237

238

\section{Coral perimeter and surface fractal dimension}

The perimeter fractal dimension, $\mathrm{D}_{\mathrm{P}}$, for the 50 corals was very close to the Euclidean value, $\mathrm{D}=1$, and it was contained within the $5 \%$ to $95 \%$ confidence interval for all corals but three (CUR34, CUR54, and CAS142) (Figure 3a). When considering the theoretical error of the box counting method (3\%), these three cases were compatible with the Euclidean value: CUR34 $\left(D_{P}=1.00 \pm 0.03\right), C U R 54\left(D_{P}=0.99 \pm 0.03\right)$, and CAS142 $\left(D_{P}=0.99 \pm 0.03\right)$. The average

fractal dimension was $\left\langle\mathrm{D}_{\mathrm{P}}>=0.999 \pm 0.03(\mathrm{SE})\right.$, and the nonparametric sign test evaluated if the individual perimeters were non-fractal as a whole (null hypothesis, $D \neq 1$ ), yielding a p-value of 0.013. This was a conservative analysis, and incorporating the theoretical error $(3 \%)$ would reduce this p-value even further. Thus, the dimensions of coral perimeters were non-fractal. The perimeters were also analyzed visually, when comparing high $\left(\mathrm{D}_{\mathrm{P}}=1.01 \pm 0.03\right)$, medium $\left(\mathrm{D}_{\mathrm{P}}=\right.$ $0.999 \pm 0.005)$, and low $\left(\mathrm{D}_{\mathrm{P}}=0.988 \pm 0.008\right)$ fractal dimensions $( \pm \mathrm{SE})$, no salient geometric feature distinguished them (Figure 3b).

The surface areas and surface fractal dimensions were measured for 50 corals within the $1 \mathrm{~mm}$ to $1 \mathrm{~m}$ range using the $3 \mathrm{D}$ coral models (Figure $3 \mathrm{a}$ ). The $5 \%$ to $95 \%$ confidence intervals 
253 included the Euclidean surface dimension, D=2, for all corals except four: CSA017 (CI: 1.94-

256 0.06) and CUR34 $\left(\mathrm{D}_{\mathrm{S}}=1.94 \pm 0.06\right)$ were compatible with the Euclidean value, while CUR40-2

$257\left(\mathrm{D}_{\mathrm{S}}=1.90 \pm 0.06\right)$ and CUR9 $\left(\mathrm{D}_{\mathrm{S}}=1.86 \pm 0.06\right)$ remained slightly lower. The average fractal

258 dimension was $\left\langle\mathrm{D}_{\mathrm{s}}>=2.00 \pm 0.06( \pm \mathrm{SE})\right.$ The nonparametric sign test evaluated if the coral

259 surfaces were fractal (null hypothesis, $D \neq 2$ ); this yielded a p-value of $1.212 \mathrm{e}-7 * * *$ using the

260 statistical confidence interval. This p-value would have been even smaller if the theoretical error

261 was included. Thus, overall coral surfaces were statistically non-fractal. Figure 3c compares

262 corals with high $(2.08 \pm 0.04)$, medium $(2.01 \pm 0.04)$, and low $(1.90 \pm 0.03)$ mean surface fractal

263 dimensions. Corals with high surface fractal dimension had no holes and their surface texture

264 was more rugose; corals with low fractal dimension instead displayed holes, peninsulas, and

265 smoother surfaces. Thus, coral surfaces were statistically non-fractal, but the mean fractal value

266 captured distinguishable geometrical features.

267

Relationship between outcomes and individual geometric variables

The absence of fractality in corals facilitated the measurement of the geometric properties

270 at a single (high-resolution) scale. The percentage of losing perimeter $(\% \mathrm{~L})$ was studied as a

271 function of geometric and biological variables using linear regression analysis (see Figure S5 and

272 Table S6). The percentage of losing perimeter $(\% \mathrm{~L})$ was negatively correlated with the surface

273 area $\left(\right.$ slope $=8.6 \pm 4.21 / \log _{10}\left(\mathrm{~cm}^{2}\right), \mathrm{R}^{2}=0.09, \mathrm{p}$-value $\left.=0.045^{*}\right)$ and the surface fractal dimension 
$274 \quad\left(\right.$ slope $=-145 \pm 45, \mathrm{R}^{2}=0.18, \mathrm{p}$-value $\left.=0.0021^{* *}\right)$. The opposite was observed for the percentage

275 of winning perimeter $(\% \mathrm{~W})$ : surface area $\left(\right.$ slope $=8.6 \pm 4.21 / \log _{10}\left(\mathrm{~cm}^{2}\right), \mathrm{R}^{2}=0.08, \mathrm{p}$ -

276 value $\left.=0.045^{*}\right)$ and surface fractal dimension $\left(\right.$ slope $=144 \pm 45, \mathrm{R}^{2}=0.18, \mathrm{p}$-value $\left.=0.0023^{* *}\right)$.

277 This is due to $\% \mathrm{~W}$ being negatively correlated with $\% \mathrm{~L}$ (slope $=-0.9 \pm 0.1, \mathrm{R}^{2}=0.8$, $\mathrm{p}$-value $=$

$\left.2782.2 \times 10^{-16 * * *}\right)$ (Figure S4). The percentage of neutral perimeter $(\% \mathrm{~N})$ was discarded due to its

279 low values (Figure 2b). Thus, two surface properties (area and fractal dimension) were directly

280 correlated with the coral competition outcomes. The fractal dimension displayed the strongest

281 correlation, but only captured $18 \%$ of the variance $\left(\mathrm{R}^{2}=0.18\right)$, and no variables related to the

282 perimeter showed a direct correlation with the outcomes.

Importance of combined geometric variables in coral-algal competition outcomes outcomes was analyzed using random forest, which estimated the average percentage increase of mean squared error $<\%$ IncMSE $>$ in predicting the losing perimeter $(\% \mathrm{~L})$ for each coral feature 288 (see Figure S6a). The variance explained using all variables was $4.3 \pm 0.6 \%$ (SE). The surface 289 fractal dimension was the most important predictor, and the only one selected statistically against 290 the null hypothesis by rfPermute ( $\mathrm{p}$-value $<0.05)$. The following variables - listed with 291 decreasing importance - were the 3D perimeter, surface area, and perimeter-to-surface ratio. The 292 lowest ranked predictor was the mean perimeter fractal dimension.

The top ranked variables were then combined separately and analyzed again using the random forest statistical model (Table S6). The optimal combination was surface fractal 
295 dimension, 3D perimeter, and species. This explained $18.7 \pm 0.5 \%(\mathrm{SE})$ of the variance, and the

$2963 \mathrm{D}$ perimeter $\left(<\%\right.$ IncMSE $>=11.0 \pm 0.3, \mathrm{p}$-value $\left.=0.036^{*} \pm 0.009\right)$ and the surface fractal

297 dimension $\left(<\%\right.$ IncMSE $>=11.0 \pm 0.4, p$-value $\left.=0.021^{*} \pm 0.007\right)$ were both equally important

298 and statistically significant ( $\mathrm{p}$-value < 0.05) (Figure S6a). These two variables alone, however,

299 explained only $\sim 8 \%$ of the variance. Combinations with other geometric variables, like the

300 perimeter-to-surface ratio, led to $\sim 17 \%$ variance explained (see Table S6). Thus, coral geometry

301 alone explained up $17 \%$ of the percentage of losing perimeter, and the surface fractal dimension

302 and $3 \mathrm{D}$ perimeter were the most relevant variables.

303

An analogous analysis was done for the \%Winning outcome. Figure S6b plots the input

variables ranked as a function of their average percentage increase of mean squared error

$305<\%$ IncMSE $>$. Surface area, perimeter-to-surface area ratio, and 3D perimeter were the better-

ranked variables, although only the surface area and 3D perimeter to surface area ratio had a

307 significant p-value (0.05). The fractal surface dimension occupied a middle-ranked position,

308 despite displaying a strong direct correlation with \%W (Figure S5b); the perimeter fractal

309 dimension was again the least relevant variable. The variance explained using all variables was

$31019.6 \% \pm 0.9 \%(\mathrm{SE})$. As in the $\%$ Losing case, the most relevant variables were re-analyzed

311 separately (Table S6). The optimal combination corresponded to the $3 \mathrm{D}$ perimeter to surface

312 ratio, $3 \mathrm{D}$ perimeter, and surface area. This explained $26.6 \% \pm 0.5 \%$ of the variance. The $3 \mathrm{D}$

313 perimeter to surface area ratio $\left(12.0 \% \pm 0.4 \%, \mathrm{p}\right.$-value $\left.=0.028^{*} \pm 0.007\right)$ and the $3 \mathrm{D}$ perimeter

$314(10.6 \% \pm 0.3 \%, p$-value $=0.020 * \pm 0.004)$ were the most important and significant variables.

315 The surface area had a similar value but the $p$-value was slightly larger ( $p$-value $=0.059 \pm$ 
0.010). The geometrical properties of corals explained $\sim 25 \%$ of the variability of $\%$ Winning outcomes, and the perimeter to surface area ratio was the strongest predictor.

Hierarchical analysis of coral outcomes and coral geometry

323 sections).

For the percent losing case $(\% \mathrm{~L})$, the nodes of the regression tree corresponded to the surface fractal dimension and 3D perimeter (see Figure 4a). Corals with a fractal dimension $\mathrm{D}_{\mathrm{S}}<$

3262 had a higher $\% \mathrm{~L}$ and were classified on the left side of the tree. Among those, corals with 3D

327 perimeters smaller than $318 \mathrm{~cm}$ formed the group with the largest percentage of losing perimeter, $328<\% \mathrm{~L}>=79 \%$. For the group with $\mathrm{D}_{\mathrm{S}}>2$, a $3 \mathrm{D}$ perimeter larger than $549 \mathrm{~cm}$ led to the cluster 329 with the lowest percentage of losing perimeter, $<\% \mathrm{~L}>=44 \%$. Figure $4 \mathrm{a}$ also displays the $\% \mathrm{~L}$ as 330 a function of the 3D perimeter and surface fractal dimension. The sectors represent the regions 331 selected by the tree. As expected, the bottom-left sector (small $\mathrm{D}_{\mathrm{S}}$ and small perimeter) had the

332 highest value of percentage losing perimeter, while the top-right sector (large $\mathrm{D}_{\mathrm{S}}$ and perimeter) 333 had the smallest percentage of losing perimeter. area $(\mathrm{SA}), 3 \mathrm{D}$ perimeter $\left(\mathrm{P}_{3 \mathrm{D}}\right)$, and $3 \mathrm{D}$ perimeter to surface area ratio $\left(\mathrm{P}_{3 \mathrm{D}} / \mathrm{SA}\right)$ as the main nodes 
337 classified on the right side of the tree. Among those, corals with small perimeter to surface area

338 ratios, $\mathrm{P}_{3 \mathrm{D}} / \mathrm{SA}<0.054 \mathrm{~cm}^{-1}$, formed the group with the largest percentage of winning perimeter,

$339<\% \mathrm{~W}>=43 \%$. On the left side of the tree, that is, $\mathrm{SA}<6482 \mathrm{~cm}^{2}$, the secondary node was based

340 on the $3 \mathrm{D}$ perimeter instead of the $3 \mathrm{D}$ perimeter to surface area ratio. Corals with large

341 perimeters, $\mathrm{P}_{3 \mathrm{D}}>141 \mathrm{~cm}$, formed the group with the lowest percentage of winning perimeter,

$342<\% \mathrm{~W}>=14 \%$. Figure $\mathrm{S} 6 \mathrm{~b}$ also plots the $\% \mathrm{~W}$ as a function of the surface area and the perimeter

343 to surface area ratio. The sectors represent the regions selected by the regression tree. As

344 expected, the bottom-right sector (large $\mathrm{SA}$ and small $\mathrm{P}_{3 \mathrm{D}} / \mathrm{SA}$ ) had the highest value of

345 percentage winning perimeter, while the top-left sector (small SA and large $\mathrm{P}_{3 \mathrm{D}}$ ) had the smallest

346 percentage of winning perimeter. Notice that corals with larger \% $\mathrm{W}$ resided in the bottom half of

347 the scatter-plot, that is, the region with smaller perimeter to surface area ratio.

349 Geometric predictors at the species level

The coral-algal competitive outcomes were also analyzed separately for species

351 represented by more than five sampled colonies: Orbicella faveolata $(\mathrm{n}=12)$, Montastraea

352 cavernosa $(\mathrm{n}=10)$, Pseudodiploria strigosa $(\mathrm{n}=8)$, and Siderastrea sidereal $(\mathrm{n}=7)$ (Figures $\mathrm{S} 7$,

$353 \mathrm{~S} 8, \mathrm{~S} 9, \mathrm{~S} 10)$. For each species, the average percentage of losing perimeter $(\% \mathrm{~L})$ as a function of

354 the surface fractal dimension $\left(\mathrm{D}_{\mathrm{s}}\right)$ and $3 \mathrm{D}$ perimeter $\left(\mathrm{P}_{3 \mathrm{D}}\right)$ (Figure $\left.\mathrm{S} 9\right)$ was compatible with the

355 values obtained for the same regions in the global analysis (Figures 4a). This was also consistent

356 for the percentage of winning perimeter (Figures S10 and 4b). Thus, the outcome averages for

357 the regions selected in the global analysis led to equivalent results at the individual species level. 
Analysis of coral geometric properties across Curaçao regions.

The corals sampled were grouped in three geographical regions: East, Central, and West

361 (Figure S1). The four main geometrical indicators for the percentage of losing and winning

362 interactions were compared using boxplots (Figure S11). The Central region showed the lowest

363 value for the fractal dimension (median $\mathrm{D}_{\mathrm{s}}<2$ ) and surface area (Figures S8a and S8b), indicating

364 a higher percentage of corals losing against algae. The East region displayed a relatively large

365 surface dimension, which was comparable to the West region $\left(\mathrm{D}_{\mathrm{s}}>2\right)$. Additionally, corals in the

366 East region displayed the largest surface area of all.

\section{DISCUSSION}

Coral geometrical properties are involved in the acquisition of resources as well as the

370 defense of corals against benthic algae, and in this we were interested in determining if larger

371 fractal dimensions and smaller perimeter-to-surface area ratios were favoring corals when facing

372 competitive interactions with algae.

373 Relation between coral geometry and coral-algal outcomes

374 Coral geometric properties explained $19-27 \%$ of the coral-algal interaction outcomes

375 (Figure S6). The surface fractal dimension was instead the best single indicator for the

376 percentage of perimeter that was losing or winning ( $\mathrm{p}$-value $=0.0021^{* *}$ and $\mathrm{R}^{2}=0.18$, Figure

377 S5). This is consistent with the coral surface being essential for harvesting energy for growth and competition. To defend its perimeter, a coral colony depends on resources acquired through 
379 photosynthesis (carried out by endosymbiotic algae) and heterotrophic feeding (Porter, 1976).

380 Losing corals had lower surface fractal dimensions $\left(\mathrm{D}_{\mathrm{S}}<2\right)$ and presented holes and large

381 peninsulas, while winning corals had higher surface fractal dimensions $\left(D_{S}>2\right)$ and displayed

382 more compact and rugose surfaces (Figure 3c). Higher perimeter-to-surface area ratios (P/SA)

383 were correlated with winning corals as a secondary indicator when the surface area of corals was

384 large enough (Figures 4b).

The multivariate statistical analysis selected the $3 \mathrm{D}$ Perimeter $\left(\mathrm{P}_{3 \mathrm{D}}\right)$, fractal surface

386 dimension $\left(D_{S}\right)$, and coral species as the most relevant variables for the percentage of losing

387 perimeter (\%L) (Figure S6a). These variables combined explained 19\% of the variance of

388 outcomes - similar to the variance explained by the surface fractal dimension alone, 18\% (Figure

389 S5a). For the percentage of winning perimeter $(\% \mathrm{~W})$, the variables selected were the 3D

390 perimeter to surface area ratio $\left(\mathrm{P}_{3 \mathrm{D}} / \mathrm{SA}\right), 3 \mathrm{D}$ perimeter $\left(\mathrm{P}_{3 \mathrm{D}}\right)$, and surface area $(\mathrm{SA})$ (Figure $\left.\mathrm{S} 6 \mathrm{~b}\right)$.

391 These variables combined explained $27 \%$ of the variance (Figure S5b). Low surface fractal

392 dimensions, $\mathrm{D}_{\mathrm{S}}<2$, were a good proxy for losing corals (Figure 4a), while large surfaces with low

393 perimeter to surface ratios favored winning corals (Figure $4 b$ ).

Implications of the fractal dimensions of coral colonies

Coral fractal dimensions have been used to differentiate coral species based on the

397 structure and texture of corallites (Martin-Garin et al., 2007), characterize coral rugosity

398 (Knudby and LeDrew, 2007), describe coral and sponge growth (Kaandorp \& Kubler, 2001), 
400

401

402

403

404

405

406

407

408

409

410

411

412

413

414

415

416

417

418

419

420

groups such as coral rubble and algal flats on large reef scales (Purkis et al., 2005, 2006; Zawada \& Brock, 2009). As shown in Figure 5, the perimeter of coral colonies (range $0.5 \mathrm{~mm}$ to $1 \mathrm{~m}$ ) displayed fractal dimensions close to the topological dimension, D 1 (current study). Larger colonies (range $0.1 \mathrm{~m}-100 \mathrm{~m}$ ) had slightly larger values, D 1.2 (Bradbury and Reichelt, 1983; Mark, 1984), and coral reefs ( $10 \mathrm{~m}-5 \mathrm{~km}$ range) displayed values on the order of $\mathrm{D} \sim 1.5$ (Purkis et al., 2006). The perimeters of seagrass beds and hard ground patches were similar, suggesting that the topography of the ground may be responsible for the increment of the fractal dimension. The surface fractal dimension of corallite sections adopted $\mathrm{D} \sim 0.8-1.0$ at the septa range $0.1 \mathrm{~mm}$ $-1 \mathrm{~mm}$ (texture) and $\mathrm{D} \sim 1.2-1.6$ at the calicular range $1 \mathrm{~mm}-1 \mathrm{~cm}$ (structure) (Martin-Garin et al., 2007). The surface of coral colonies (1 mm - $1 \mathrm{~m}$ range) adopted fractal dimensions around the topological value, $\mathrm{D} \sim 1.85-2.15$. Coral reefs $(0.5 \mathrm{~m}-5 \mathrm{~km}$ range $)$ displayed larger values D 2.28-2.61 (Zawada and Brock, 2009), which could be associated to the rugosity of the ground as in the case of the perimeter. Thus, the perimeter and surface fractal dimensions increase at larger scales.

At the coral colony scale, the perimeter and surface dimensions were compatible with the Euclidean dimensions, $\mathrm{D}=1$ and $\mathrm{D}=2$, respectively (Figure 3). This justifies modeling coral colonies using Euclidean geometries (Meesters \& Bak, 1996; Jackson, 1977; Naumann et al., 2009). The mean values of the surface fractal dimension, however, correlated with coral outcomes (Figure S5) and identified salient geometrical features. Corals with mean fractal dimensions smaller than two, $\mathrm{D}_{\mathrm{S}}<2$, displayed surfaces with holes and large peninsulas, while corals with fractal dimensions larger than two, $\mathrm{D}_{\mathrm{S}}>2$, displayed more compact surfaces with 
421 richer and more wrinkled textures (Figure 3c). Additional geometric metrics such as rugosity,

422 vector dispersion, multivariate multiscale fractal dimension, and multifractal analysis (Reichert

423 et al., 2017; Young et al., 2017, Chakraborty et al., 2016) might be necessary to refine the coral

424 geometric analysis presented here.

425

The open regions observed in corals with a surface fractal dimensions smaller than two,

426 Ds $<2$, can represent more space for algae to occupy, thus leading to the DOC-Disease-Algae-

427 Microbes (DDAM) positive feedback loop detrimental for those coral colonies (Dinsdale \&

428 Rohwer, 2011; Haas et al., 2011; Barott et al., 2012a, Roach et al., 2017). This lower fractal

429 dimension associated to holes aligns also with the fact that corals have a limited capacity to

430 regenerate lesions, and if they are larger than a certain size they may never be closed (Meesters

431 et al., 1997). In fact, the sites sampled in the Central region of Curacao had a significantly lower

432 surface fractal dimension than the East and West regions (see Figure S11). The combination of

433 the geometrical properties and the decision trees (Figure 4) suggested that the East region is the

434 healthiest region of Curaçao, followed by the West and Central regions. This analysis is

435 consistent with field observations (Barrot et al. 2012c) and confirms the applicability of the

436 geometrical analysis of corals as a proxy to assess coral-algal interactions.

438 Conclusions and Perspectives

The geometrical properties of corals explained $19 \%$ to $27 \%$ of coral-algal competition

440 outcomes. The perimeter and surface dimensions of coral colonies were non-fractal, but the

441 mean surface fractal dimension displayed the strongest correlation with coral-algal interaction 
442 outcomes. Losing corals had low surface fractal dimensions $\left(\mathrm{D}_{\mathrm{S}}<2\right)$ and displayed holes and

443 large peninsulas, while winning corals $\left(D_{S}>2\right)$ were more compact and displayed more rugose

444 surfaces. Winning corals had larger surface areas with lower perimeter to surface area ratios,

445 confirming that coral surfaces play a key energetic role in sustaining corals against algal attacks.

446 The main geometrical predictors selected from the global analysis partitioned the percentage of

447 losing and winning perimeters of individual species consistently. Additional data for individual

448 species, however, will be necessary to confirm the relationship between geometrical properties

449 and coral-algal interaction outcomes. Surveying the surface area and fractal dimensions of corals

450 in other regions will help validate the generality of these results. Nevertheless, more

451 sophisticated techniques such as multifractal analysis, might be necessary to understand why the

452 surface fractal dimension is statistically non-fractal while displaying the strongest correlation

453 discerning losing and winning corals. Additionally, it will be necessary to incorporate other

454 descriptors that impact coral outcomes such as microbial and viral communities to achieve more

455 accurate predictions.

456

457 Acknowledgements

We acknowledge Mark Hate for the original artwork that was adapted to generate the

459 method figure about the reconstruction of 2D and 3D corals. We also thank and acknowledge the

460 support of our funding sources. The work of Forest Rohwer and Aaron Hartmann was funded by

461 the PIRE grant: NSF Partnerships for International Research and Education Grant (1243541). Ty

462 N.R. Roach work was supported by the National Science Foundation (G00009988). 


\section{Literature Cited}

465

466

467

468

469

470

471

472

473

474

475

476

477

478

479

480

481

482

483

484

485

486

487

488

489

490

491

492

493

494

495

496

497

498

499

500

501

502
1. Archer E. 2016. rfPermute: Estimate Permutation p-Values for Random Forest

2. Importance Metrics. R package version 2.1.5. https://CRAN.Rproject.org/package $=$ rfPermute

3. Barott KL, Rohwer FL. 2012a. Unseen players shape benthic competition on coral reefs. Trends in Microbiology 20: 621-628.

4. Barott K, Williams G, Vermeij M, Harris J, Smith J, Rohwer F, Sandin S. 2012b. Natural history of coral-algae competition across a gradient of human activity in the Line Islands. Marine Ecology Progress Series 460:1-12.

5. Barott K, Rodriguez-Mueller B, Youle M, Marhaver KL, Vermeij M, Smith J, Rohwer F. 2012c. Microbial to reef scale interactions between the reef-building coral Montastratea annularis and benthic algae. Proc. R. Soc. B 279:1655-1664.

6. Basillais E. 1997. Coral surfaces and fractal dimensions: a new method. Comptes rendus de l'Académie des sciences 320:653-657.

7. Basillais E. 1998. Functional role of the fractal morphology of corals: a full model of the nutrient turbulent diffusion fluxes to a coral reef. C. R. Acad. Sci. Paris, Sci. de la vie 321, 295- 298.

8. Bradbury RH, Reichelt RE. 1983. Fractal dimension of a coral reef at ecological scales. Marine Ecology Progress Series 10:169-171.

9. Budd AF, Fukami H, Smith ND, Knowlton N. 2012. Taxonomic classification of the reef coral family Mussidae (Cnidaria: Anthozoa: Scleractinia). Zoological Journal of the Linnean Society, 166(3), 465-529.

10. Burkepile, DE, Hay, ME. 2006. Herbivore vs. nutrient control of marine primary producers: context-dependent effects. Ecology 87:3128-3139.

11. Burns J, Delparte D, Gates, Takabayashi M. 2015. Integrating structure-from-motion photogrammetry with geospatial software as a novel technique for quantifying $3 \mathrm{D}$ ecological characteristics of coral reefs. PeerJ 3:e1077.

12. Buss LW, Jackson JBC. 1979. Competitive Networks: Nontransitive Competitive Relationships in Cryptic Coral Reef Environments. 
13. Chakraborty B, Vardhan YV, Haris K, Menezes A, Karisiddaiah SM, Fernandes WA, Kurian J. (2016). Multifractal detrended fluctuation analysis to compare coral bank and seafloor seepage area-related characterization along the central western continental margin of India. IEEE Geoscience and Remote Sensing Letters, 13: 1542-1546.

14. Dinsdale EA, Rohwer F. 2011. Fish or germs? Microbial dynamics associated with changing trophic structures on coral reefs. In: Dubinsky, Z, Stambler, N, editors. Coral reefs: an ecosystem in transition. Dordrecht: Springer Verlag: 231-240.

15. Endara M-J, Coley PD. 2011. The resource availability hypothesis revisited: a metaanalysis. Functional Ecology, 25, 389-398.

16. Falconer K. 2003. Fractal geometry: Mathematical foundations and applications. Wiley, $2^{\text {nd }} \mathrm{Ed}$.

17. Gracias N, Santos-Victor J. 2000. "Underwater video mosaics as visual navigation maps." Computer Vision and Image Understanding 79(1): 66-91.

18. Gracias N, Santos-Victor J. 2001. Underwater mosaicing and trajectory reconstruction using global alignment. OCEANS, 2001. MTS/IEEE Conference and Exhibition.

19. Grottoli, AG et al. 2006. Heterotrophic plasticity and resilience in bleached corals. Nature $440,1186-1189$

20. Haas AF, Nelson CE, Wegley-Kelly L, Carlson CA, Rohwer F, Leichter JJ, Wyatt A, Smith JE. 2011. Effects of coral reef benthic primary producers on dissolved organic carbon and microbial activity. PLoS One 6:e27973.

21. Haas AF, Gregg AK, Smith JE, Abieri ML, Hatay M, Rohwer F. (2013). Visualization of oxygen distribution patterns caused by coral and algae. PeerJ, 1, e106.

22. Halley JM, Hartley S, Kallimanis AS, Kunin WE, Lennon JJ, Sgardelis SP. 2004. Uses and abuses of fractal methodology in ecology. Ecology Letters 7:254-271.

23. Henry L.A., Hart M. 2005. Regeneration from injury and resource allocation in sponges and corals-a review. International review of hydrobiology 90(2):125-158.

24. Hughes TP. 1989. Community structure and diversity of coral reefs: the role of history. Ecology 70:275-279.

25. Jackson JBC. 1977. Competition on marine hard substrata: the adaptive significance of solitary and colonial strategies. American Naturalist 11: 743-767. 
26. Jackson JBC. 1979. Morphological strategies of sessile animals. In Larwood, G. \& B. R. Rosen (eds), Biology and Systematics of Colonial Organisms. Systematics Association, Special Volume 11. Academic Press, London: 499-555.

27. Jackson JBC, Winston JE. 1982. Ecology of cryptic coral reef communities: Distribution and abundance of major groups of encrusting organisms.

28. Johnston I S, Rohwer F. 2007. Microbial landscapes on the outer tissue surfaces of the reef-building coral Porites compressa. Coral Reefs, 26(2), 375-383.

29. Kaandorp JA, Kubler JE. 2001. The Algorithmic Beauty of Seaweeds, Sponges and Corals. Berlin: Springer-Verlag: 193.

30. Knudby A, LeDrew E. (2007). Measuring Structural Complexity on Coral Reefs.

31. Lavy A, Eyal G, Neal B, Keren R, Loya Y, Ilan M. (2015). A quick, easy and nonintrusive method for underwater volume and surface area evaluation of benthic organisms by 3D computer modelling. Methods in Ecology and Evolution, 6(5), 521-531.

32. Leon JX, Roelfsema CM, Saunders M, Phinn SR. 2015. Measuring coral reef terrain roughness using 'Structure-from-Motion' close-range photogrammetry, Geomorphology, 242: 21-28.

33. Lesser MP. 2000. Depth-dependent photoacclimatization to solar ultraviolet radiation in the Caribbean coral Montastraea faveolata. Marine Ecology Progress Series 192, 137

34. Lesser MP, Slattery, M., Stat, M., Ojimi, M., Gates, R. D. and Grottoli, A. (2010). Photoacclimatization by the coral Montastraea cavernosa in the mesophotic zone: light, food, and genetics. Ecology 91, 990-1003.

35. Liaw A, Wiener M. (2002). Classification and Regression by randomForest. R News 2(3), 18-22

36. Lirman D. 2001. Competition between macroalgae and corals: Effects of herbivore exclusion and increased algal biomass on coral survivorship and growth. Coral Reefs 6 (19): 392-399.

37. Lirman D, et al. 2007. Development and application of a video-mosaic survey technology to document the status of coral reef communities. Environmental Monitoring and Assessment 125(1-3): 59-73. 
38. Lirman D, et al. 2010. Damage and recovery assessment of vessel grounding injuries on coral reef habitats by use of georeferenced landscape video mosaics. Limnology and Oceanography: Methods 8(3): 88-97.

39. Madl P, Witzany G. 2014. How corals coordinate and organize: an ecosystemic analysis based on biocommunication and fractal properties. In: Witzany $\mathrm{G}$ (ed) Biocommunication of animals, Springer Science+Business Media, Dordrecht, Germany, $351-382$

40. Mandelbrot B. 1967. How long is the coast of Britain? Statistical self-similarity and fractional dimension. Science 156 (3775): 636-638.

41. Mandelbrot BB. (1977). Fractals: Form, chance, and dimension. San Francisco: Freeman. 365.

42. Mandelbrot BB. (1983). The fractal geometry of nature, (updated and augmented edition). New York: Freeman. 468.

43. Martin-Garin B, Lathuiliere B, Verrecchia EP, Geister J. 2007. Use of fractal dimensions to quantify coral shape. Coral Reefs $26: 541-550$.

44. Mark D. Fractal dimension of a coral reef at ecological scales: a discussion. 1984 Marine Ecology Progress Series 14:293-294.

45. McCook, L, Jompa, J, Diaz-Pulido, G. 2001. Competition between corals and algae on coral reefs: a review of evidence and mechanisms. Coral Reefs 19:400-417.

46. Meesters EH, Wesseling I, Bak RPM. 1996. Partial mortality in three species of reefbuilding corals (Scleractinia) and the relation with colony morphology. Bulletin of Marine Science 58: 838-852.

47. Meesters EH, Pauchli W, Bak RPM. 1997. Predicting regeneration of physical damage on a reef-building coral by regeneration capacity and lesion shape. Mar Ecol Prog Ser 146: 91-99.

48. Naumann MS, Niggl W, Laforsch C, Glaser C, Wild C. (2009). Coral surface area quantification-evaluation of established techniques by comparison with computer tomography. Coral reefs, 28(1), 109-117.

49. Okie JG. (2013). General models for the spectra of surface area scaling strategies of cells and organisms: fractality, geometric dissimilitude, and internalization. The American Naturalist, 181(3), 421-439. 
647

648

649

650

651

652

653

654

655

656

657

658

659

660

661

662

663

664

665

666

667

668

669

670

50. Oren U, Rinkevich B, Loya Y. 1997. Oriented intra-colonial transport of 14 C labeled materials during regeneration in scleractinian corals. Marine Ecology Progress Series 161:117-121.

51. Oren U, Benayahu Y, Lubinevsky H, Loya Y. 2001. Colony integration during regeneration in the stony coral Favia favus. Ecology 82:802-813.

52. Pandolfi JM, Jackson JBC 2006. Ecological persistence interrupted in Caribbean coral reefs. Ecol Lett 9: 818-826.

53. Perry CT, Edinger EN, Kench PS, Murphy GN, Smithers, SG, Steneck, RS, Mumby PJ. (2012). Estimating rates of biologically driven coral reef framework production and erosion: a new census-based carbonate budget methodology and applications to the reefs of Bonaire. Coral Reefs, 31(3), 853-868.

54. Porter JW. 1976. Autotrophy, heterotrophy, and resource partitioning in Caribbean reefbuilding corals. American Naturalist 110:731-42.

55. Precht WF, Aronson RB. 2006 Death and resurrection of Caribbean coral reefs: a paleoecological perspective. In Coral reef conservation pp. 40-77. Cambridge, UK: Cambridge University Press.

56. Purkis SJ, Riegl B. (2006). Fractal patterns of coral communities: evidence from remote sensing (Arabian Gulf, Dubai, UAE).

57. Rasher, DB, Engel, S, Bonito, V, Fraser, GJ, Montoya, JP, Hay, ME. 2012. Effects of herbivory, nutrients, and reef protection on algal proliferation and coral growth on a tropical reef. Oecologia 169:187-198.

58. Reichert J, Backers AR, Schubert P, Wilke T. 2017. The power of 3D fractal dimensions for comparative shape and structural complexity analyses of irregularly shaped organisms. Methods Ecol Evol 0, 1-9.

59. Rinkevich B, Loya Y. 1989. Reproduction in regenerating colonies of the coral Stylophora pistillata. Pages 257-265 in E. Spanier, Y. Stinberger, and M. Luria, editors. Environmental quality and ecosystem stability. Hebrew University, Jerusalem, Israel.

60. Roach TNF, Abieri ML, George EE, Knowles B, Naliboff DS, Smurthwaite CA, WegleyKelly L, Haas AF, Rohwer FL. 2017. Microbial bioenergetics of coral-algal interactions. PeerJ 5:e3423. 
61. Silveira, CB, Silva-Lima, AW, Francini-Filho, RB, Marques, JSM, Almeida, MG, Thompson, CC, Rezende, CE, Paranhos, R, Moura, RL, Salomong, PS, Thompson, FL. 2015. Microbial and sponge loops modify fish production in phase-shifting coral reefs. Environ Microbiol 17:3832-3846.

62. Smith, JE, Hunter, CL, and Smith, CM. 2010. The effects of top-down versus bottom-up control on benthic coral reef community structure. Oecologia 163:497-507.

63. Sebens KP. 1982. Competition for space: Growth rate, reproductive output, and escape in size.

64. Schweinsberg M, Weiss LC, Striewski S, Tollrian R, Lampert KP. 2015. More than one genotype: how common is intracolonial genetic variability in scleractinian corals? Molecular Ecology (11):2673-85.

65. Swierts T, Vermeij MJ. (2016). Competitive interactions between corals and turf algae depend on coral colony form. PeerJ 4:e1984 https://doi.org/10.7717/peerj.1984

66. Tanner JE. 1995. Competition between scleractinian corals and macroalgae: an experimental investigation of coral growth, survival and reproduction. Journal of Experimental Marine Biology and Ecology 190:151-168.

67. Terry T, Atkinson B, and Ripley B. (2017). rpart: Reursive partitioning and regression trees. R package version 4.1-11. https://CRAN.R-project.org/package=rpart

68. Zawada DG, Brock JC. (2009). A multiscale analysis of coral reef topographic complexity using lidar-derived bathymetry. Journal of Coastal Research, 6-15.

69. Young GC, Dey S, Rogers AD, Exton D. (2017). Cost and time-effective method for multiscale measures of rugosity, fractal dimension, and vector dispersion from coral reef 3D models. PLoS One 124: e0175341. 


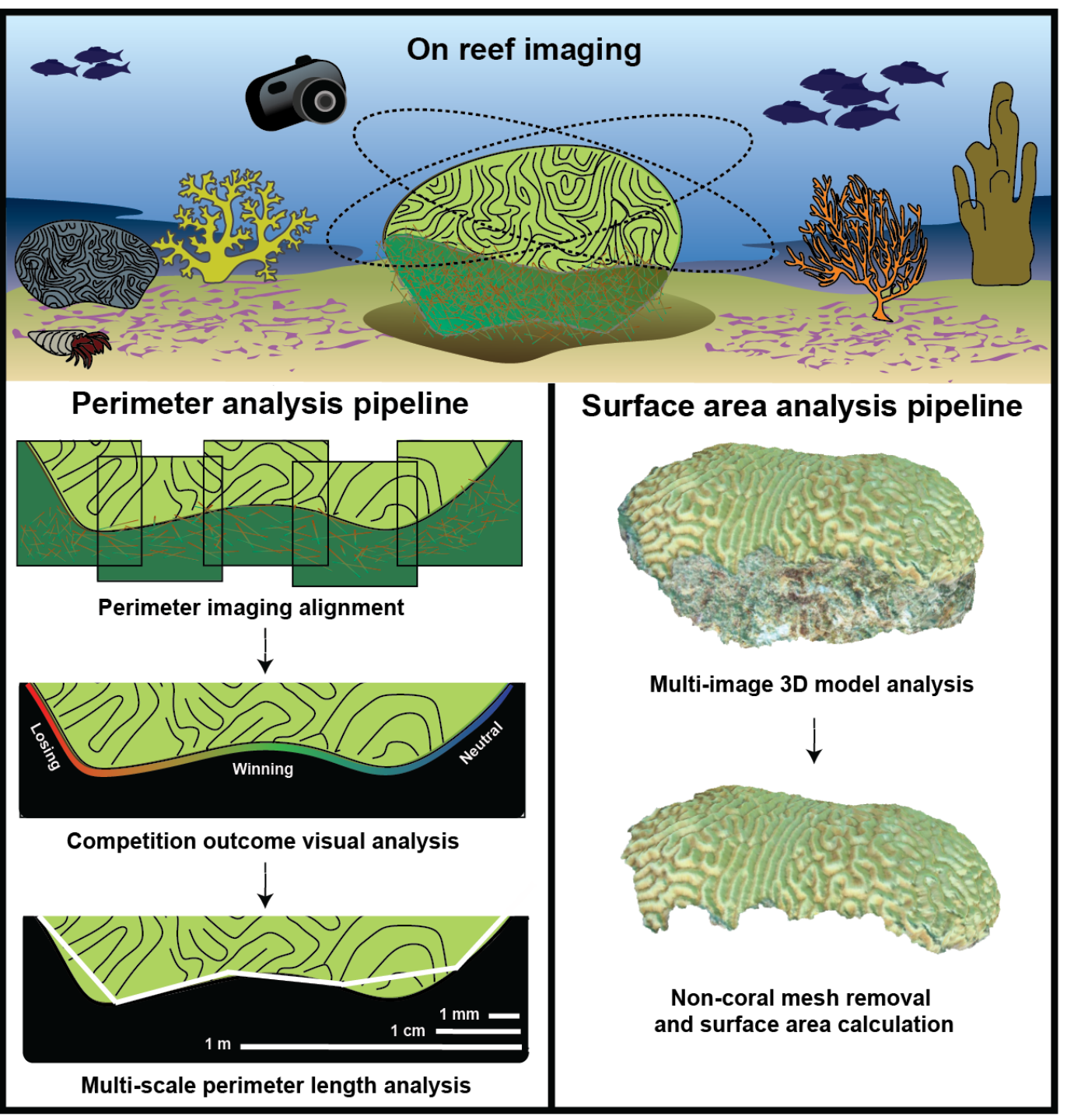

Figure 1. Coral geometry methods (Top panel) Corals were photographed from different angles and distances. (Bottom left panel) Close range pictures were stitched together to generate a high-resolution 2D perimeter model. The interactions along the coral perimeter were outlined and the perimeter lengths were measured over a $0.1 \mathrm{~mm}$ to $1 \mathrm{~m}$ scale range. (Bottom right panel) Farther range pictures were processed to create the 3D coral models. Models were calibrated with an in-reef reference; non-coral mesh was removed to measure the coral surface area. 
bioRxiv preprint doi: https://doi.org/10.1101/327031; this version posted May 24, 2018. The copyright holder for this preprint (which was not certified by peer review) is the author/funder, who has granted bioRxiv a license to display the preprint in perpetuity. It is made available under aCC-BY 4.0 International license.

a) 2D and 3D representative models for increasing percentage of loosing perimeter

\begin{tabular}{|c|c|c|c|c|}
\hline$\%$ Losing & $20 \%$ & $46 \%$ & $75 \%$ & $92 \%$ \\
\hline $\begin{array}{c}\text { 2D perimeter } \\
\text { projection }\end{array}$ & & & & \\
\hline $\begin{array}{c}\text { 3D Coral } \\
\text { Surface Model }\end{array}$ & & & & \\
\hline
\end{tabular}

b) Statistics for the competitive outcomes

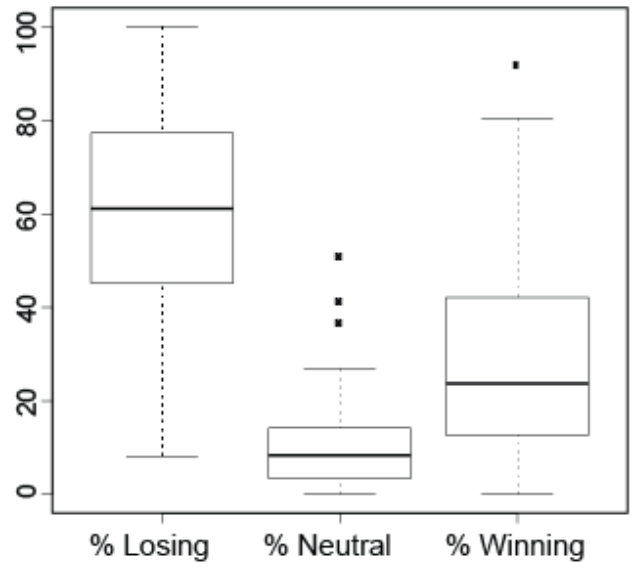

c) Competitive outcomes across species

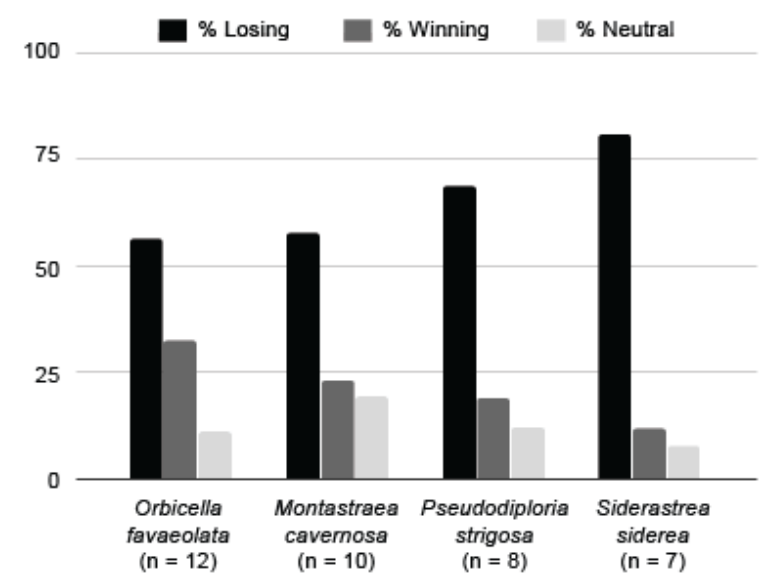

Figure 2. Coral models and statistics for competitive outcomes. a) $2 \mathrm{D}$ and $3 \mathrm{D}$ coral models for different percentages of losing perimeter $(\% \mathrm{~L})$. The $2 \mathrm{D}$ models highlight the losing regions in red. $\mathrm{b})$ Box plot for the three perimeter outcomes: losing $(\% \mathrm{~L})$, neutral $(\% \mathrm{~N})$, and winning $(\% \mathrm{~W})$. The middle line corresponds to the median, the range of the box contains from the $25^{\text {th }}$ to the $75^{\text {th }}$ percentile, and each whisker is the minimum (in absolute value) between the $150 \%$ interquartile range (IQR) and the value of the most extreme point in that side of median. Outliers exceeding the whiskers are included (Table S5). b) Competitive outcomes for species that were sampled in five or more colonies. The bars correspond to the average percentage of losing perimeter (black), average percentage of winning perimeter (dark grey), and average percentage of neutral perimeter (light grey). 


\section{Coral Fractal Dimensions}

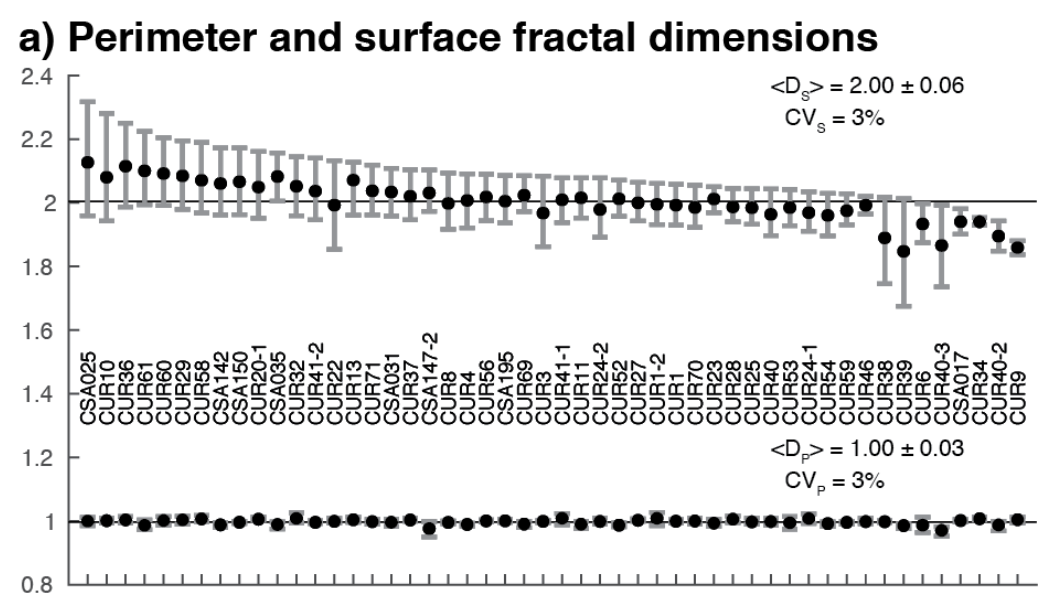

\section{b) Fractal perimeter representatives}
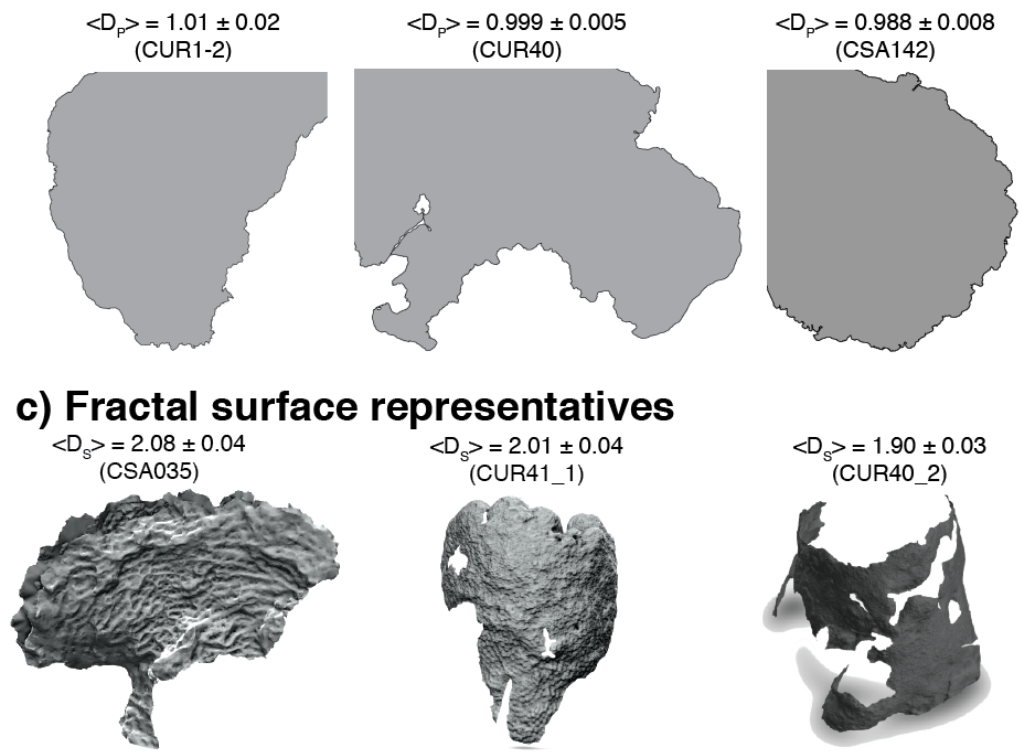

Figure 3. Coral fractal dimensions. a) Surface fractal dimensions (top) and perimeter fractal dimensions (bottom) for all specimens reconstructed digitally. The plot includes the mean (black dot), 5 to $95 \%$ confidence intervals (whiskers), and the label associated to each coral. A solid line provides a reference for the topological dimensions: $\mathrm{D}$ $=1$ (perimeter) and $\mathrm{D}=2$ (surface). The plot includes also the mean values for the fractal dimension of the perimeter $\left(<\mathrm{Dp}_{\mathrm{p}}>\right)$ and the surface $\left(<\mathrm{Ds}_{\mathrm{S}}>\right)( \pm$ standard deviation $)$ and their respective coefficients of variation $(\mathrm{CV}=$ standard deviation / mean * 100). Panels b) and c) display coral representatives associated with high, medium, and low fractal dimension for the perimeter (b) and the surface (c).

\section{$\left\langle D_{g}>=2.01 \pm 0.04\right.$}
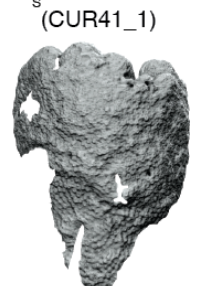

$$
\left\langle D_{S}>=1.90 \pm 0.03\right.
$$

(CUR40_2)

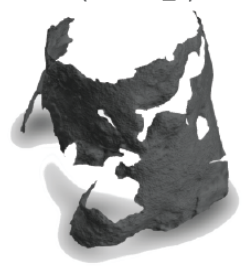




\section{Interdependence of Optimal Variables in the Prediction of Outcomes}

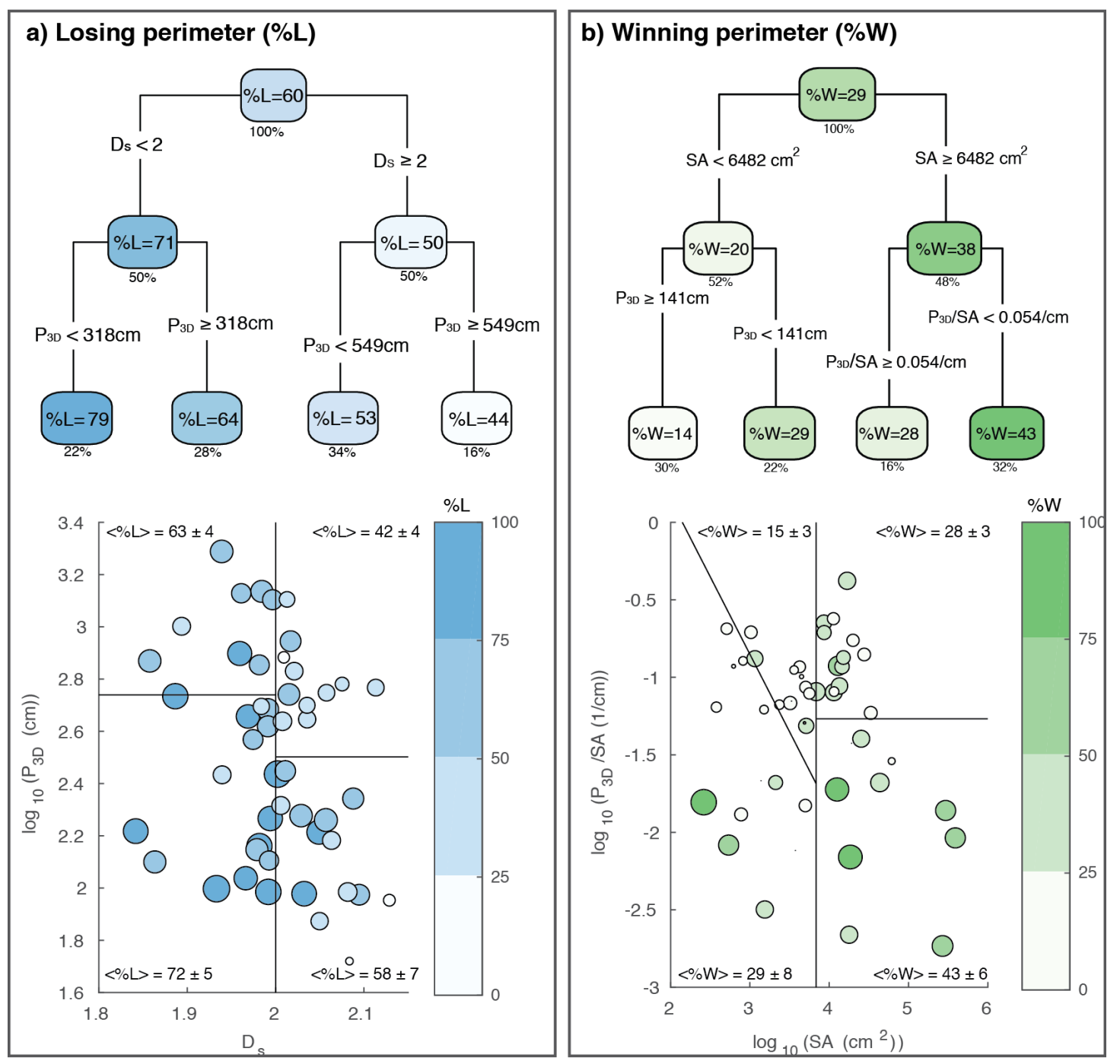

Figure 4. Interdependence of optimal variables in the predictions of outcomes. a) A regression tree (top panel) generated for the percentage losing perimeter $(\% \mathrm{~L})$ including the selected variables in the refined Random Forest analysis (Figure S6). Each cluster displays the average outcome. The value below the box indicates the percentage of data contained in the cluster. The bottom panel plots $\% \mathrm{~L}$ as a function of the $3 \mathrm{D}$ Perimeter and fractal surface dimension. The shades of blue and circle sizes are proportional to the level of $\% \mathrm{~L}$. $b$ ) The two panels are analogous to a) but using the percentage of winning perimeter $(\% \mathrm{~W})$ as an output variable. The percentage of winning is in this case proportional to the intensity of green. 


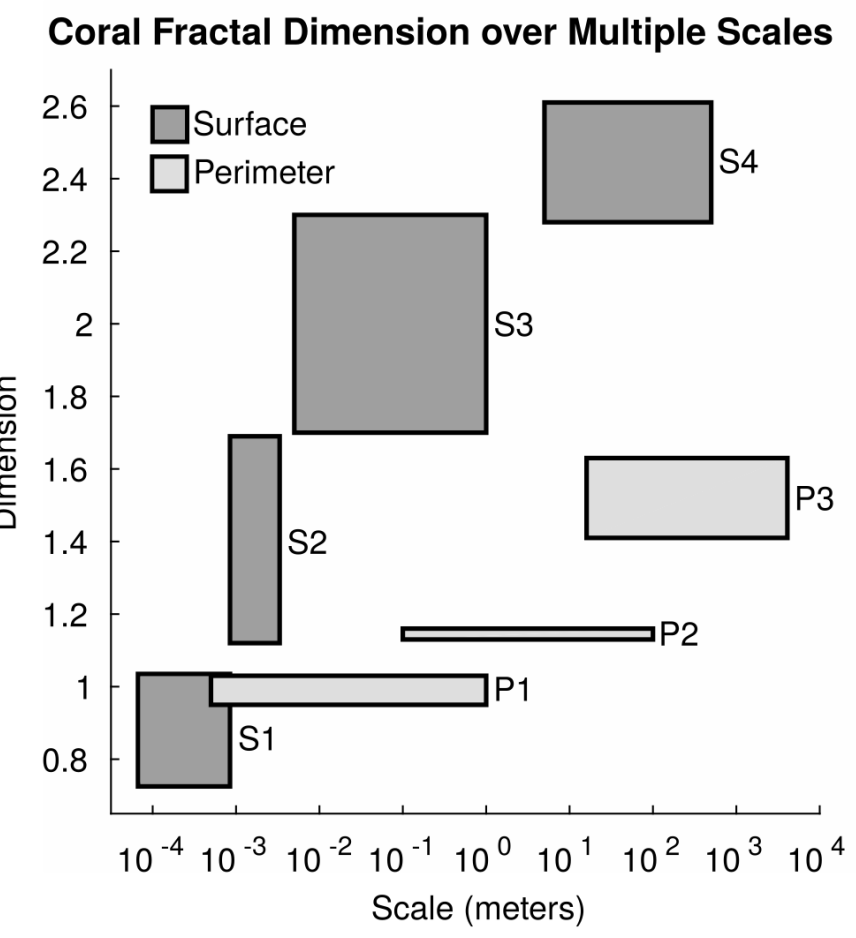

Figure 5. Coral fractal dimension over multiple scales. The chart plots the ranges of fractal dimensions measured across scales for different coral studies. The fractal dimensions are grouped in two categories: Surface fractal dimension (dark grey) and perimeter fractal dimension (light grey). For the perimeter, the ranges correspond to coral colonies (P1; current study), larger coral colonies (P2; Bradbury \& Rachel, 1983; Mark, 1984), and coral reefs (P3; Purkis et al., 2006). For the surface, the ranges correspond to corallite texture (S1; Martin-Garin et al., 2007), corallite structure (S2; Martin-Garin et al., 2007), coral colonies (S3; current study), and coral reefs (S4; Zawada et al., 2009). 